\title{
Can Music Increase Empathy? Interpreting Musical Experience Through The Empathizing- Systemizing (E-S) Theory: Implications For Autism
}

\author{
DAVID M. GREENBERG \\ University of Cambridge \\ PETER J. RENTFROW \\ University of Cambridge \\ SIMON BARON-COHEN \\ University of Cambridge
}

\begin{abstract}
Recent research has provided evidence that musical interaction can promote empathy. Yet little is known about the underlying intrapersonal and social psychological processes that are involved when this occurs. For example, which types of music increase empathy and which types decrease it; what role, if any, does empathy play in determining individual differences in musical preference, perception, and performance; or, how do these psychological underpinnings help explain the musical experiences of people with autism spectrum conditions (ASC). To address these questions we employ the Empathizing-Systemizing (E-S) theory as a fruitful framework in which to understand these music-related phenomena. Specifically, we explore how individual differences in musical preference, perception, and performance can be explained by E-S theory. We provide examples from open-ended descriptions of strong musical experiences to demonstrate the ways in which empathy and music inter-relate. Importantly, we discuss the implications for the study of autism, and for how music therapists and clinicians can use music as a tool in their work with individuals diagnosed with ASC.
\end{abstract}

Submitted 2014 April 29; accepted 2014 June 29.

KEYWORDS: empathy, autism, musical preference, perception, performance

EMPATHY is a fundamental feature of human interaction. It requires both cognitive (Dennett, 1989; Baron-Cohen, 1995) and affective (Davis, 1994) components that enable people to recognize the emotional and mental states of others, and to respond to these with appropriate emotions (Harris, Johnson, Hutton, Andrews, \& Cooke, 1989; Baron-Cohen \& Wheelwright, 2004). Empathy allows for the perception of another's thoughts and feelings, and allows one to predict how they will behave (Whiten, 1991). Music listening and performance, which is a universal feature of human behavior (Blacking, 1995), also requires components of cognitive and affective processing. We listen and are exposed to music for hours each day (Motion Picture Association of America, Inc, 2007; Rentfrow, 2012), during which time we perceive the emotional and psychological content in music; interpret the thoughts, feelings, and proficiency of the musicians from auditory and visual cues (Thompson, Russo, \& Quinto, 2008; Tsay, 2013); respond emotively to the music and the musician (Juslin, \& Västfjäll, 2008; Zentner, Grandjean, \& Scherer, 2008), and can predict the direction of a melodic phrase or narrative. Empathy is thus connected with the perception, interpretation, and emotional reactions to music.

However, only recently have researchers in the field of music, personality, and social psychology begun to focus on how music and empathy are linked. For example, Wöllner (2012) showed that people with higher levels of empathy are able to perceive and identify a musician's intentions with greater accuracy than those with lower levels, and Egermann and McAdams (2013) demonstrated that perceived and induced emotion from music is moderated by empathy. Further, not only does empathy influence 
physiological reactions to music (Miu \& Balteş, 2012), but Vuoskoski and colleagues have shown that empathy is associated with susceptibility to induced sadness from music (Vuoskoski \& Eerola, 2012), and also enjoyment of sad music (Vuoskoski, Thompson, McIlwain, \& Eerola, 2012). Researchers have also suggested that music increases prosocial behavior in children (Kirschner \& Tomasello, 2010), adolescence (Rickson \& Watson, 2003) and adults (Greitemeyer, 2009). Finally, recent research by Rabinowitch, Cross, and Burnard (2013) demonstrated that long-term group musical interaction conducted for an hour once a week increases emotional empathy in children aged 8-11 years old.

The study of empathy has implications for individuals diagnosed with autism spectrum conditions (ASC), who traditionally have lower levels of cognitive empathy (also known as "theory of mind" or "mentalizing") than the general population (Baron-Cohen, 1995). Individuals with ASC have unusual perceptual abilities and affective reactions to music. For example, those with ASC have enhanced accuracy in pitch processing (Heaton, 2003, 2005) and pitch discrimination (Bonnel et al., 2003, 2010). However, adolescents with ASC are less accurate at detecting emotional expressivity in musical performance (Bhatara et al., 2010). Although research has suggested that individuals with ASC do not have deficits in emotional categorization (Quintin, Bhatara, Poissant, Fombonne, \& Levitin, 2011), reports of emotional reactivity to music by individuals with ASC are different compared to the general population (Allen, Hill, \& Heaton, 2009). Importantly, there is clear evidence that both short (Whipple, 2004; Kaplan \& Steele 2005) and long-term (Boso, Emanuele, Minazzi, Abbamonte, \& Politi, 2007) music therapy interventions improve a range of behaviors in individuals with autism. Specifically, these interventions can reduce impairments in communication and motor skills (Accordino, Comer, \& Heller, 2007).

One of the main limitations of the existing research on music as it relates to both empathy and autism is that it focuses only on empathy and does not measure a related dimension of the mind which has been argued to be linked to empathy: systemizing (Baron-Cohen, Richler, Bisarya, Gurunathan, \& Wheelwright, 2003).[1] Whereas empathy is the cognitive and affective capacity to understand and react appropriately to the feelings and mental states of others (Baron-Cohen \& Wheelwright, 2004), systemizing is the capacity to construct, analyze, and predict systems, including those that are natural (e.g. weather or tidal systems), abstract (e.g. mathematics), organizational (e.g. classifications), and technical (e.g. the construction of a musical instrument or mechanical motor) (Baron-Cohen, 2002; Baron-Cohen et al., 2003). These two dimensions of individual differences are the basis of the Empathizing-Systemizing (E-S) theory (Baron-Cohen, 2003, 2009).

In this paper we suggest that E-S theory provides a fruitful framework through which to expand knowledge about individual differences in music-related processes, and to fill gaps in theory and research into music as it relates to empathy and autism. The aims of this paper are to:

1. Review E-S theory and describe related research;

2. Explore how E-S theory can help to interpret individual differences in musical preferences, perception, and performance;

3. Outline how each of these three musical constructs has implications for understanding music and autism;

4. Propose how music can increase empathy in both the general population and individuals with ASC, and identify the psychological processes involved.

\section{EMPATHIZING-SYSTEMIZING THEORY}

For over a decade, E-S theory has provided clear theoretical and empirical evidence that offer explanations for psychological sex differences (Baron-Cohen, 2003), cognitive styles (Billington, Baron-Cohen, \& Wheelwright, 2007), and autism (Baron-Cohen, Knickmeyer, \& Belmonte, 2005a). Operationally, empathizing is the drive to "predict and to respond to the behavior of agents (usually people) by inferring their mental states and responding to these with an appropriate emotion," where systemizing is the drive to "predict and to respond to the behavior of nonagentive deterministic systems by analyzing input-operationoutput relations and inferring the rules that govern such systems" (Baron-Cohen et al., 2005b, p. 819).

Within the E-S framework, empathizing is measured by the Empathy Quotient (EQ; Baron-Cohen \& Wheelwright, 2004), and includes items such as: "I can pick up quickly if someone says one thing but means another"; "I am good at predicting how someone will feel"; and "other people tell me I am good at understanding how they are feeling and what they are thinking." Those that score higher on the EQ also score higher on emotion recognition tasks such as the "Reading the Mind in the Eyes" test (Chapman et al., 
2006). Systemizing is measured by the Systemizing Quotient (SQ; Baron-Cohen et al., 2003), and includes items such as: "I am fascinated by how machines work"; "In math, I am intrigued by the rules and patterns governing numbers"; and "If I were buying a computer, I would want to know exact details about its hard disc drive capacity and processor speed." Those that score higher on the SQ tend to study subjects related to the physical sciences rather than humanities (Billington, Baron-Cohen, \& Wheelwright, 2007).

Comparing an individual's scores on both empathizing (E) and systemizing (S) reveals their "brain type," or "cognitive style." Individuals with E $>$ S scores are categorized as Type E; those with S $>$ E are categorized as Type $\mathrm{S}$; and those with relatively equal $\mathrm{E}$ and $\mathrm{S}$ scores are categorized as Type B (i.e. balanced). The difference in scores on the EQ and SQ also reveal cognitive styles on the extreme end; those with $\mathrm{E}>>\mathrm{S}$ scores are categorized as Extreme Type E, and those with $\mathrm{S}>\mathrm{E}$ scores are considered Extreme Type S. In terms of psychological sex differences, more females are Type E and more males are Type S (Baron-Cohen et al., 2005a).

E-S theory has direct implications for autism.[2] Scores on the EQ and SQ predict scores on the Autism Spectrum Quotient (AQ; Baron Cohen, Wheelwright, Skinner, Martin, \& Clubley, 2001; Goldenfeld, Baron-Cohen, \& Wheelwright, 2005), which measures autistic traits as a continuum among both the general population and individuals with ASC diagnoses. The "Extreme Male Brain" theory (EMB; Baron-Cohen, 2002), an extension of E-S theory, argues that individuals with autism have lower levels of empathy alongside intact or elevated levels of systemizing. Individuals with ASC (of which there is a greater prevalence in males; Fombonne, 2005) are more likely to have a brain type of Extreme Type S (Goldenfeld et al., 2005). Furthermore, research has demonstrated a neurobiological basis supporting these differences in cognitive styles and brain types. Measurements of amniotic fluid during the second trimester of pregnancy have revealed increased fetal testosterone in those with higher autistic traits or with autism (Auyeung et al., 2009; Baron-Cohen et al., 2011). Recent research shows that elevated systemizing in males is associated with larger hypothalamic and ventral basal ganglia regions in the brain (Lai et al., 2012), and that females with ASC differ from typical females largely in those brain regions in which typical males and females differ, supporting the EMB theory (at least for females).

E-S theory is grounded in empirical and neurological evidence, providing a framework in which to better understand musical phenomena. Interpreting individual differences in musical-related constructs in terms of levels of empathizing and systemizing will help to illuminate the underlying psychological processes involved in musical experience. Specifically, it may broaden our understanding of how music can increase empathy, and importantly, may have direct implications for the study of autism. Furthermore, the neurobiological foundations of E-S theory have the potential to complement and extend previous cognitive and physiological research into music. In the following sections, we describe how E-S theory may explain differences in musical preference, perception, and performance; the implications for autism; and the theoretical reasoning on how music can increase empathy.

\section{MUSICAL PREFERENCES}

Why do people like the music that they do? Music spans a vast multi-dimensional space covering a wide spectrum of sonic (e.g. timbre, instrumentation, and harmonic progression) and psychological (e.g. sadness, anger, joy, aggressiveness, energy, and emotional depth) characteristics and themes (e.g. love, heartbreak, rebellion, and redemption). Of course, all the combinations and forms produced by these musical attributes have their own fan-base. For example, some prefer music that is loud, percussive, fast, intense, and aggressive, as in the heavy metal and rock genres. At these concerts fans can be seen jumping up and down, forming mosh pits, and lifting each other over the crowd. Others prefer music that is slow to medium speed in tempo, and which has mellow, gentle, and romantic characteristics, as in the R\&B and soul genres. At these concerts fans dance to the music and sing along with the lyrics. And some prefer music that is more instrumental, complex, and varied, as in classical and jazz genres. At these concerts fans are often sitting down and listening intently to the music, and waiting for either the composition or improvised solo to be finished before applauding or cheering. What determines these marked differences in musical preferences?

Early personality psychologists such as Cattell and colleagues argued that musical preferences are manifestations of non-conscious aspects of personality, which provide a window into understanding the unconscious mind (Cattell \& Anderson, 1953; Cattell \& Saunders, 1954). However today, researchers (Rentfrow, Goldberg, \& Levitin, 2011; Bonneville-Roussy, Rentfrow, Xu, \& Potter, 2013) have adopted an approach aligned with interactionist theories (Buss, 1987; Swann, Rentfrow, \& Guinn, 2002), positing that people seek out music and musical environments that reflect and reinforce more explicit and observable 
characteristics and traits. The correlations between musical preferences and psychological constructs such as personality traits (Rentfrow \& Gosling, 2003), values (Boer et al., 2011) and age demographics (Bonneville-Roussy et al., 2013) have been studied, and convergence across many studies from varied geographical regions (Rentfrow \& Gosling, 2003; George, Stickle, Rachid, \& Wopnford, 2007; Delsing, ter Bogt, Engels, \& Meeus, 2008; Zweigenhaft, 2008; Brown, 2012; Dunn, de Ruyter, \& Bouwhuis, 2012; Langmeyer, Guglhör, \& Tarnai, 2012) has provided clear evidence that these constructs are linked in a similar fashion. Extraverts for example prefer music that is "upbeat and conventional" (pop, soundtrack, and religious genres) and "energetic and rhythmic" (soul/funk and electronic/dance genres), and people high in Openness to Experience prefer "reflective and complex" music (blues, jazz, classical and folk genres) (Rentfrow \& McDonald, 2009).

Yet, less is known about the role that empathy plays in musical preferences.[3] This is particularly surprising considering that emotional recognition, interpretation, and feeling are so central to music listening. And just as musical preferences appear to be, in part, manifestations of personality traits and values, it is reasonable to expect that given the emotionally communicative nature of music, people's preferences may be driven by their empathy levels. These varying levels of empathy are likely to impact the types of music that people choose to listen to, not only in the long-term, but also in the short-term, depending on temporary fluctuations in empathy.

Rentfrow and colleagues provided evidence that people's musical preferences can be organized into five robust dimensions defined as the MUSIC music-preference model (Rentfrow et al., 2011, 2012). By using musical excerpts, these researchers overcame limitations presented by genre-labels[4] with the benefit of observing the specific sonic and psychological attributes in the music that participants preferred. These attributes were found to transparently differentiate each of the five music preferences dimensions:

1. Mellow (featuring romantic, relaxing, unaggressive, sad, slow, and quiet musical attributes; as in soft rock, R\&B, and adult contemporary genres);

2. Unpretentious (uncomplicated, relaxing, unaggressive, soft, and acoustic; as in country, folk, and singer/songwriter genres);

3. Sophisticated (inspiring, intelligent, complex, and dynamic; as in classical, operatic, avant-garde, world beat, and traditional jazz genres);

4. Intense (distorted, loud, and aggressive, but not relaxing or romantic; as in classic rock, punk, heavy metal, and power pop genres);

5. Contemporary (percussive and electric, but not sad; as in rap, electronica, Latin, acid jazz, and Euro pop genres).

To address whether these five dimensions emerged within preferences for a single genre, Rentfrow et al. (2012) asked participants to indicate their preferences for a set of 50 jazz excerpts, and then asked a separate sample to indicate their preferences for a set of 50 rock excerpts. In each sample, the same fivefactor structure emerged demonstrating that the MUSIC model is not bound by genres or social connotations attached to genre-labels, but is rather driven by the sonic and psychological attributes in music.

Which of the specific musical attributes and five musical preference dimensions do individuals who are Type E ("empathizers") prefer? Those with higher levels of empathy have a capability to perceive, recognize, and react to a wide range and depth of emotion, and therefore experience and encounter such in their everyday lives. It would be reasonable to expect that if music preferences are a reflection of empathy levels, that empathizers will prefer music that contain emotional, deep, reflective, romantic, and gentle attributes. These attributes are predominant features of the Mellow music-preference dimension. Music that would fall under the Mellow dimension, like Norah Jones' "Don't Know Why" or Jeff Buckley's version of "Hallelujah," are likely appeal to empathizers because they reflect the emotional depth that empathizers experience in their daily lives. Individuals who are Type S ("systemizers"), who have a greater tendency to perceive and react to systems and patterns, including those that are natural and abstract, are likely to select music with features that reinforce these tendencies. Music that has a more explicit mathematical basis for example, which contains complex harmonic, rhythmic, and melodic patterns and devices are likely to appeal to the systemizer. Systemizers may have a drive to decode such musical patterns in the same way that they would tend to decode the mechanics of a car engine or a city map. They may be drawn to music that contains complex sonic combinations and diverse instrumentation, which acts as a "musical puzzle" that can be deconstructed and organized. Therefore, systemizers are likely to prefer music that is featured in 
the Sophisticated music-preference dimension. A distinction will need to be made between emotional and sonic sophistication, as systemizers may prefer the latter and empathizers the former. Importantly, because systemizers also have lower levels of empathy and do not recognize and react to emotion as well as empathizers, systemizers are likely to prefer music that is opposite of that which is featured in the Mellow dimension, including music with energetic, thrilling, and forceful attributes, which are features of the Intense dimension. Therefore, the music of the Red Hot Chili Peppers, Nirvana, or Metallica may be appealing to systemizers as well.

What are the implications for autism? Because individuals with ASC are often categorized as Extreme Type S, they are likely to prefer music that contains a plethora of patterns, complex instrumentation, and complicated harmonic and rhythmic systems; that is, the extreme end of Sophisticated or the extreme end of Intense music. Avant-garde classical or jazz music may be particularly appealing. For example, those with ASC may find music that features 12-tone harmony, one of the more complex harmonic systems in western music, particularly interesting. Also, music featuring polyrhythms (i.e. music featuring two opposing rhythms) may be of interest.

However, just because individuals with ASC have lower levels of cognitive empathy does not mean that they do not also listen to music for emotional purposes. Coinciding with interactionist theories which argue that people seek out environments that are a reflection of the self, Joni Mitchell said in an interview: "The trick is if you listen to that music and you see me, you're not getting anything out of it. If you listen to that music and you see yourself, it will probably make you cry and you'll learn something about yourself and now you're getting something out of it."[5] Individuals with ASC may like the music that they do, because they are able to see aspects of themselves in the music. Perhaps certain characteristics, themes, and messages in the music reflect what it is like to live with autism.

To help shed light on this notion, we asked individuals formally diagnosed with ASC to provide open-ended responses describing their "...strongest, most intense experience with music" (see Gabrielsson, 2011; Lamont, 2011, 2012).[6] One participant poignantly pointed out the mirror-like reflection music can serve for individuals with ASC:

My strongest reactions to music are usually one of three: 1) Songs that convey how it feels to live with autism-I have many favourite songs where I feel this is the case even though it was not the intention of the songwriter. They tend to convey either the confusion of the autistic person as they look around at the world, the desire for freedom and to escape from the neurotypical world, or on a darker note, anger born out of mistreatment directed at neurotypicals...2) Songs/music about heroism-heroes are usually individuals who walk alone like people with autism, and this music usually lifts my mood and actually stirs emotion...3) Music that conveys a feeling of other worlds/plains of existence etc. as it ties in with the idea of autistics not feeling like they came from Earth. This includes lots of world/alternative music and some movie soundtracks. (a 37 year-old male with Asperger syndrome)

This response, although anecdotal, is very powerful, and shows how the psychological characteristics in music can help illuminate the phenomenological experience of individuals with ASC. If those with ASC are "seeing" themselves in the music that they like, how is what they are hearing different than those from typically developing populations? For this question we turn to the study of music perception.

\section{MUSICAL PERCEPTION}

It is worth considering the relevance of E-S theory for the study of music perception, and in particular, rhythmic perception. Individuals with different cognitive impairments have unusual musical abilities, characterized by both strengths and weaknesses (Levitin et al., 2003). For example, individuals with Williams syndrome (WS) display enhanced emotional reactions to music (Don, Schellenberg, \& Rourke, 2009). Although individuals with WS have poor spatial and reasoning abilities, they have a greater rate of perfect pitch than the general population (Lenhoff, Perales, \& Hickock, 2001) and their rhythmic perception remains intact, and in some cases even elevated (Levitin \& Bellugi, 1998). Further, Huss and colleagues found that children with dyslexia are less accurate in detecting rhythmic meter change than children in typically developing populations (Huss et al., 2011). 
Differences in empathizing and systemizing may also be underlying differences in rhythmic ability. For example, empathizers are likely to have a greater ability at identifying emotions and may focus more on the emotional content of music rather than the sonic attributes. Systemizers on the other hand, are likely to focus more on the sonic elements rather than the emotional. It is quite reasonable to expect that although individuals with ASC may be less accurate at identifying emotion in music than typically developing populations, they may display strengths as it relates to the perception of sonic features. This hypothesis is also compatible with the "weak coherence" account (Frith, 1989), which helps explain both enhanced abilities and deficits in perceptual processing of individuals with ASC.

Frith and colleagues showed that the typical developing population processes incoming perceptual information by attaching meaning to it, at the expense of paying attention to the detail or surface structure of the perceptual information (Happé \& Frith, 2006). This is referred to as "central coherence." Individuals with ASC who have weak central coherence have difficulty grasping the "bigger picture," but have an enhanced tendency for a more detailed-focused processing style. This concept has crossovers with hypersystemizing theory (which shares overlaps, but also differs from weak coherence theory; see Baron-Cohen et al., 2009), which proposes that hyper-systemizers have excellent attention to detail, both perceptually and in memory, driven by the search for patterns in data. Musically, these theories have been supported by research demonstrating that individuals with ASC have greater accuracy in pitch perception (Miller, 1999), and a greater ability to remember and identify pitches over time (Heaton, Hermelin, \& Pring, 1998).

These concepts have implications for rhythmic perception as well. As part of a study on musical sophistication, Müllensiefen, Gingras, Musil, and Stewart (2014) asked participants from the general population to complete a beat perception task adopted from Iverson and Patel (2008). Participants were presented with several musical excerpts from a variety of genres. A metronomic beep was played over each excerpt. Specifically, the metronomic beep was manipulated to either have the same tempo as the musical excerpt, and therefore considered to be "on the beat," or was manipulated to be slower or faster in tempo than that of the excerpt, and therefore considered to be "off the beat." Participants had to indicate whether or not the metronomic beep was "on the beat" or "off the beat." On average, males were significantly more accurate than females in identifying whether or not the metronomic beep coincided with the actual tempo of each excerpt. Although the reasons for these sex differences remain unknown, these differences may reflect differences in empathizing and systemizing. The systemizers' greater attention to detail and detailprocessing is likely at the root of such differences. Where empathizers are more likely to be processing the emotional content (i.e. the "bigger picture" and global meaning of the psychological attributes in music), systemizers are likely to be more focused more on the surface content (the instrumentation and sonic attributes). And since males tend to score higher on systemizing compared to females, it is no surprise that males performed better on the beat perception task in Müllensiefen et al.'s (2014) study. Accordingly, we predict that individuals with ASC will also perform better on such tasks. Confirming these conclusions is a natural next step for future research.

\section{MUSICAL PERFORMANCE}

When discussing the psychology of musical ability and sophistication, it is also important to address musical performance and play. However, rather than proficiency, this section focuses on differences in performance style and expression. Just as preferences for music covers a large multi-dimensional musical space, so does musical expression. For example, saxophonists John Coltrane and Stan Getz, although both commonly labeled as jazz musicians, had very different tones; Getz's tone was soft and filled with vibrato, while Coltrane's was often loud, intense, and particularly early in his career, featured almost no vibrato at all. Furthermore, their approaches and styles varied greatly. Getz was associated with the west coast or "cool" jazz movement which featured softer, more melodic and relaxed attributes, while Coltrane's music, especially later in his career, was associated with the avant-garde movement, characterized by greater tension, intensity, and dissonance. Such differences in musical performance may be explained, at least partially, by E-S theory.

A fitting example comes from the personal experience of the first author, who a few years ago took music lessons with two prominent jazz musicians in New York City. Within the span of one month, both teachers were separately asked the same question: "How do you express emotion through your instrument?" The first teacher, Sean (for purposes of anonymity, the teachers' names presented here are fictitious), answered by notating two measures of a musical phrase and then described that his approach is to first deconstruct the musical line into its smallest parts, learn and analyze it, and then to put it back 
together again; like taking apart a car engine and then reconstructing it for the purpose of seeing how each individual part produces the whole. He proceeded to explain that each emotional expression has a technical structure that produces the subsequent expression through the instrument. The homework he gave was to deconstruct a musical line, to learn each part individually first, and then to put it back together again.

Several weeks later, the second teacher, Terry, when asked the same question, answered too by notating two measures of a musical phrase. But, rather than deconstructing it, he played it on his instrument and described that in order to express an emotion, a musician must first dig deep and search for where the feeling is located in the musical line. He argued that the reason why any musician is motivated to play anything at all is because they feel it inside first. The homework he gave was to dig deep and search for the emotion in each musical phrase and scale that was being learned.

The responses from these two teachers varied greatly. Both provide incredibly valuable insights into music but they vary in terms of their perspective. It can be argued that Sean has a more systemizing approach and Terry has a more empathizing approach. Importantly, both are considered to be at the top of the jazz idiom, but they appear to have achieved their mastery via different routes. These differences may reflect aspects of empathizing and systemizing, which invite many questions for future psychological research.

Do musicians across styles and genres vary based on their levels of empathizing and systemizing? For example, are classical musicians more likely to be systemizers, and are $\mathrm{R} \& \mathrm{~B} / \mathrm{soul}$ musicians more likely to be empathizers? Do levels of empathizing-systemizing predict musical success? Is it more beneficial to learn certain aspects of music theory (e.g. rhythm) from a systemizing approach, but others (e.g. harmony) from an empathizing approach? Is it possible to interpret the music and personal characteristics of some of the foremost musical geniuses (e.g. Bach, Beethoven, and Brahms) in terms of E$\mathrm{S}$ theory? Do differences in empathizing and systemizing translate into differences in physical movement and expression in musical performance?[6]

An important question that also remains is how music can be used to help support individuals with ASC. Individuals with ASC often have difficulties feeling connected to people and the social environment surrounding them, often leading to feelings of isolation, frustration, and confusion. One of the impairments of autism is in the perception, expression, and communication of emotion. Music, however, can potentially act as a medium in which individuals with ASC can communicate emotion in a manner that is different from typical activities in everyday life, potentially facilitating a sense of group cohesion and leading to feelings of social connection. This remains to be tested, but one individual with ASC described their strongest musical experience as follows:

My most intense experiences of music all involve performing as part of the music rather than just listening. A typical intense reaction would involve body-wide tingling and feelings of warmth, a feeling of experiencing both joy and despair at the same time, lightheadedness, a feeling of harmony and belonging with the other musicians and a feeling like there is an expanding balloon in my chest. (a 24 year-old female with Asperger syndrome)

Music, therefore, can act as an alternative medium through which those with ASC can communicate both ideas and emotions. In this way, through music, people with autism can experience themselves and the world around them in a way that is different from what they are normally accustomed. After practice within musical group play, these experiences can be potentially carried over to non-musical activities in their daily lives. Indeed, this is the belief of many musical therapists.[7] These experiences may not only improve communication skills, but may also boost confidence, and through the expression of emotion, lead to a greater sense of self.

\section{WHAT TYPES OF MUSIC INCREASE EMPATHY?}

Group musical interaction promotes empathy (Rabinowitch, Cross, \& Burnard, 2013), but it is still not clear what types of music increase empathy, and whether music listening alone can increase empathy. This is an important next step for research. Kidd and Castano (2013) conducted a series of internet studies that showed that reading literary fiction can improve both cognitive and affective theory of mind as opposed to reading non-fiction. These results are encouraging because their investigative techniques can extend to the 
medium of music. Similar methods via the internet can be devised using musical excerpts rather than reading materials. But the question remains, which types of musical stimuli are likely to increase empathy?

The correlations between musical preferences and empathy will provide an initial clue. If our predictions prove correct, that empathy is positively correlated with preferences for emotional, deep, reflective, romantic, and gentle musical attributes (music of the Mellow music-preference dimension), it is reasonable to expect that music with these attributes are likely to enhance empathy, in comparison to music that has thrilling, energetic, and forceful attributes (music of the Intense music preference dimension). What are the psychological underpinnings to why music in the Mellow dimension, which often features attributes that are sad and tearful, promote empathy over the Intense dimension, which often features musical attributes of anger and aggression?

These psychological processes might best be supplemented with clinical psychological interpretations. The concept of theory of mind, but extended to clinical applications, is the concept of mentalizing. Mentalizing contains both reflective and interpersonal components that enable the cognitive and affective ability to understand and react to the thoughts and feelings of both the self and others (Fonagy, Gergely, Jurist, \& Target, 2002). The mental processes that underlie the capacity for mentalizing is often referred to as reflective functioning (Fonagy, Target, Steele, \& Steele, 1998). Applied to the study of musical preferences, those with greater mentalizing capabilities should prefer the same type of music that empathizers do, music of the Mellow dimension, and those with less mentalizing capabilities should prefer music of the Intense dimension.

Importantly, the concept of mentalizing addresses the psychoanalytic realm of defenses (Fonagy, Moran, Edgcumbe, Kennedy, \& Target, 1993). Due to reduced reflective functioning and mentalizing ability, a person can misinterpret what they are feeling: that is, they can think that they are feeling one way but truly be feeling another (Fonagy et al., 2002). For example, anger, aggression, and violence are associated with low mentalizing (Fonagy, 2004)[8] and hinder reflective functioning. Therefore, people who listen to music with angry, aggressive, and forceful attributes may be reinforcing their feelings of anger and aggression, and obstructing empathy and reflective functioning. Listening to music that features reflective, thoughtful, and gentle attributes may therefore increase empathy and improve reflective functioning. Furthermore, improved empathy may lead to "mentalized affectivity" (Fonagy et al., 2002; Jurist, 2005), which leads to a better understanding of one's feelings gained through affect regulation. Therefore, music can potentially be used as a tool to enhance these emotional pathways and to help a person interpret the causes of negative emotions such as anger.[9]

A prime example of this psychological process is that which occurs during grieving (Kübler-Ross, 1969) where anger, denial, and bargaining often precede depression (sadness) and then finally, acceptance. Although these feelings can occur in a varied order of emergence and even simultaneously, it can be argued that anger, denial, and bargaining are defenses associated with lower mentalizing, which precedes depression. And typically, depression then precedes acceptance. When the ability to mentalize about a situation is increased, then the underlying sadness and afterward, acceptance can be realized. It may be that music, particularly for those who are deeply and frequently engaged with it, can help during the grieving process. All of these ideas need empirical testing.

In addition to collecting responses about strong musical experiences from individuals with ASC, we also collected responses from typically developing participants across several cultures. One respondent from Japan described how music helped during the grieving process:

It was "Supernova" by Bump of Chicken. In the summer 2004, when my oldest son committed suicide at the age of 17 and I was in the abyss of despair. I came across this tune on CATV. "However little it was, it was evidence of life." "There was surely the evidence of his life." "The existence remains even the body disappears." I was wailing, for many days.[10]

When asked about the specifics in the music that caused the experience, he responded: "The lyrics." And when asked how he felt immediately after the experience, he responded: "I found hope in my life." This example suggests how music was able to increase his mentalizing and reflective functioning, helping him to transition from depression and despair, to acceptance. 


\section{CONCLUSION}

Music is a powerful tool and can help individuals regulate emotions, overcome difficult situations, and find joy in their everyday life. By understanding how E-S theory explains individual differences in musical experiences, researchers can better understand how music can increase empathy and reflective functioning in both the general population and in individuals with ASC. Importantly, this line of research can extend to the study of group processes. There has been some evidence to show that music can decrease stereotypes towards out-groups (Sousa, Neto, \& Mullet 2005), and increase in-group favoritism (Bakagiannis \& Tarrant, 2006; Londsdale \& North, 2009) and prosocial behavior (Greitemeyer, 2009). Anecdotally, orchestras such as Daniel Barenboim's West Eastern Divan Orchestra (Cheah, 2009) have shown that people can use music to overcome cultural boundaries, and increased empathy may be a facilitating factor in these social psychological processes. Gaining a firm grasp on the specifics of these music-related processes will not only help inform music therapists and clinicians about how music can be used in individual and group therapeutic treatments, but it can also inform lay individuals about how to use music as a guide or "pocket therapist" that is only one click away on the iPod or mobile phone.

\section{ACKNOWLEDGEMENTS}

We are very grateful to Adam Formal, Arielle Bonneville-Roussy, Brent Clickard, and Brian Monteiro for their comments on early drafts of this paper and for helpful discussions on this topic.

\section{NOTES}

[1] For one exception, see Kreutz, Schubert, \& Mitchell (2008).

[2] E-S theory is an extension of the theory of "mindblindness," and posits that those with ASC have lower levels of cognitive empathizing (also known as "theory of mind" or "mind-reading") than the general population (Baron-Cohen et al., 2005).

[3] Nettle (2007) has argued that empathy is indistinct from personality traits. However, although sympathy overlaps with one of the six facets of the trait Agreeableness as measured and conceptualized in the Five Factor Model of personality (FFM: Digman, 1990; McCrae \& Costa, 2003), sympathy is only a facet of empathy. Specifically, it is a facet that overlaps with both the affective and cognitive (theory of mind) components of empathy (see Figure 1 in Baron-Cohen \& Wheelwright, 2004). The EQ has several facets of its own, including cognitive empathy, emotional reactivity, and social skills (Lawrence, Shaw, Baker, Baron-Cohen, \& David, 2004). Further, Wakabayashi, Baron-Cohen, \& Wheelwright (2006) found that the $\mathrm{AQ}$, which is predicted by scores on the EQ and $\mathrm{SQ}$, is a separate and distinct construct than those defined by the FFM.

[4] Fundamental limitations that researchers encounter when studying musical preferences are those that arise from using genre-based methodologies. Genres are broad and ill-defined classifications describing musical styles that contain a large spectrum of musical information. For example, the rock genre label includes artists from The Beatles and Bob Dylan, to U2 and Sting, to AC/DC and Guns N' Roses. These groups vary greatly on their instrumentation, intensity, emotional content, year of production, and even geographic origin of the artist(s). People of different ages and socio-economic and cultural backgrounds can have very different ideas and conceptions about what defines a genre. Therefore, a participant may have strict preferences for music like The Beatles, and not Guns N' Roses, but on a genre-based test their preference for rock music can be applied to both. Ultimately, the participants' preferences for specific musical characteristics are bypassed, creating problems for researchers who are then unable to identify the specific musical attributes that people are attracted to.

[5] This quote is taken from an exclusive CBC interview with Joni Mitchell (conducted by Jian Ghomeshi), which aired on CBC Radio One's Q on June 11, 2013. A video version of the interview was aired on CBCTV on June 16, 2013 (both the video and audio versions can be accessed at www.cbc.ca). 
[6] This line of questioning does not have to be limited to the realm music and can extend to other artistic mediums. Acting, for example, requires elevated levels of theory of mind (e.g. Goldstein, Wu, \& Winner, 2009). But actors too have varying approaches. Method acting (see Strasberg, 1987) which stems from Constantin Stanislavski encourages actors to access emotional and sense memory, and to make the actions of the character as "real" as possible. For method actors, acting is reacting, and the reaction should be a personal one for the actor. Such an approach may require a high level of empathizing. On the other hand, varying approaches put more of an emphasis on technique and argue that subjective emotion can hinder an actor's performance, suggesting what seems to be a more systemizing approach. Painting is another example where we see the fingerprints of empathizing and systemizing. Paintings by Claude Monet and Marc Chagall contrast greatly to those by George Braque or Marcel Duchamp. Certain movements in art such as expressionism may be an expression of empathizing, whereas some contemporary and modern art movements may express a greater level of systemizing. We can even find traces of empathizing and systemizing within a single artist's career: Picasso's "blue period" was perhaps more representative of his empathizing, while his transition to Cubism was more representative of his systemizing.

[7] One such example is the Nordoff Robbins centers for music therapy (http://www.nordoffrobbins.org.uk/ and http://steinhardt.nyu.edu/music/nordoff).

[8] Peter Fonagy and colleagues suggest that the ability to mentalize stems from parental attachment in childhood. Children who have a secure attachment with parental figures develop a greater ability to mentalize than children who develop an insecure attachment with the parental figure(s) (Fonagy, Steele, Steele, Moran, \& Higgitt, 1991; Fonagy \& Target, 1997).

[9] Peters (this volume) argues that musical empathy initiates "embodied knowledge."

[10] This response was given in Japanese and later translated to English by a professional translator.

\section{REFERENCES}

Accordino, R., Comer, R., \& Heller, W. B. (2007). Searching for music's potential: A critical examination of research on music therapy with individuals with autism. Research in Autism Spectrum Disorders, 1(1), 101-115.

Allen, R., Hill, E., \& Heaton, P. (2009). 'Hath charms to soothe...' An exploratory study of how highfunctioning adults with ASD experience music. Autism, 13(1), 21-41.

Auyeung, B., Baron-Cohen, S., Ashwin, E., Knickmeyer, R., Taylor, K., \& Hackett, G. (2009). Fetal testosterone and autistic traits. British Journal of Psychology, 100(1), 1-22.

Bakagiannis, S., \& Tarrant, M. (2006). Can music bring people together? Effects of shared musical preference on intergroup bias in adolescence. Scandinavian Journal of Psychology, 47(2), 129-136.

Baron-Cohen, S. (1994). How to build a baby that can read minds: Cognitive mechanisms in mindreading. Cahiers de Psychologie Cognitive/ Current Psychology of Cognition, 13, 513-552.

Baron-Cohen, S. (1995). Mindblindness: An essay on autism and theory of mind. Boston, MA: MIT Press/Bradford Books.

Baron-Cohen, S. (2002). The extreme male brain theory of autism. Trends in Cognitive Sciences, 6(6), 248254.

Baron-Cohen, S. (2003). Essential difference: Men, women, and the extreme male brain. London: Penguin.

Baron Cohen, S. (2009). Autism: The Empathizing-Systemizing (E S) Theory. Annals of the New York Academy of Sciences, 1156(1), 68-80. 
Baron-Cohen, S., Ashwin, E., Ashwin, C., Tavassoli, T., \& Chakrabarti, B. (2009). Talent in autism: Hyper-Systemizing, hyper-attention to detail and sensory hypersensitivity. Philosophical Transactions of the Royal Society B: Biological Sciences, 364(1522), 1377-1383.

Baron-Cohen, S., Knickmeyer, R. C., \& Belmonte, M. K. (2005a). Sex differences in the brain: Implications for explaining autism. Science, 310(5749), 819-823.

Baron-Cohen, S., Lombardo, M. V., Auyeung, B., Ashwin, E., Chakrabarti, B., \& Knickmeyer, R. (2011). Why are autism spectrum conditions more prevalent in males? PLoS Biology, 9(6), e1001081.

Baron-Cohen, S., Richler, J., Bisarya, D., Gurunathan, N., \& Wheelwright, S. (2003). The Systemizing Quotient: An investigation of adults with Asperger syndrome or high-functioning autism, and normal sex differences. Philosophical Transactions of the Royal Society of London. Series B: Biological Sciences, 358(1430), 361-374.

Baron-Cohen, S., \& Wheelwright, S. (2004). The Empathy Quotient: An investigation of adults with Asperger syndrome or high functioning autism, and normal sex differences. Journal of Autism and Developmental Disorders, 34(2), 163-175.

Baron-Cohen, S., Wheelwright, S., Lawson, J., Griffith, R., Aswhin, C., Billington, J., \& Chakrabarti, B. (2005b). Empathizing and systemizing in autism spectrum conditions. In F. Volkmar, A. Klin, \& R. Paul (Eds.), Handbook of autism and pervasive developmental disorders: Vol. 1. Diagnosis, development, neurobiology, and behavior (3rd ed., pp. 628-639). Hoboken, New Jersey: John Wiley and Sons.

Baron-Cohen, S., Wheelwright, S., Skinner, R., Martin, J., \& Clubley, E. (2001). The Autism-Spectrum Quotient (AQ): Evidence from Asperger syndrome/high-functioning autism, males and females, scientists and mathematicians. Journal of Autism and Developmental Disorders, 31(1), 5-17.

Bhatara, A., Quintin, E. M., Levy, B., Bellugi, U., Fombonne, E., \& Levitin, D. J. (2010). Perception of emotion in musical performance in adolescents with autism spectrum disorders. Autism Research, 3(5), 214-225.

Billington, J., Baron-Cohen, S., \& Wheelwright, S. (2007). Cognitive style predicts entry into physical sciences and humanities: Questionnaire and performance tests of empathy and systemizing. Learning and Individual Differences, 17(3), 260-268.

Blacking, J. (1995). Music, culture, and experience: Selected papers of John Blacking. London: University of Chicago Press.

Boer, D., Fischer, R., Strack, M., Bond, M. H. Lo, E., \& Lam, J. (2011). How shared preferences in music creates bonds between people: Values as the missing link. Personality and Social Psychology Bulletin, 113.

Bonnel, A., McAdams, S., Smith, B., Berthiaume, C., Bertone, A., Ciocca, V., Burack, J. A., \& Mottron, L. (2010). Enhanced pure-tone pitch discrimination among persons with autism but not Asperger syndrome. Neuropsychologia, 48(9), 2465-2475.

Bonnel, A., Mottron, L., Peretz, I., Trudel, M., Gallun, E., \& Bonnel, A. M. (2003). Enhanced pitch sensitivity in individuals with autism: a signal detection analysis. Journal of Cognitive Neuroscience, 15(2), 226-235.

Bonneville-Roussy, A., Rentfrow, P. J., Xu, M. K., \& Potter, J. (2013). Music through the ages: Trends in musical engagement and preferences from adolescence through middle adulthood. Journal of personality and social psychology, 105(4), 703. 
Boso, M., Emanuele, E., Minazzi, V., Abbamonte, M., \& Politi, P. (2007). Effect of long-term interactive music therapy on behavior profile and musical skills in young adults with severe autism. The Journal of Alternative and Complementary Medicine, 13(7), 709-712.

Brown, R. A. (2012). Music preferences and personality among Japanese university students. International Journal of Psychology, 47(4), 259-268.

Buss, D. M. (1987). Selection, evocation, and manipulation. Journal of Personality and Social Psychology, 53, 1214-1221.

Cattell, R. B. \& Anderson, J. C. (1953). The measurement of personality and behavior disorders by the I.P.A.T. music preference test. Journal of Applied Psychology, 37, 446-454.

Cattell, R. B. \& Saunders D. R. (1954). Musical preferences and personality diagnosis: A factorization of one hundred and twenty themes. Journal of Social Psychology, 39, 3-24.

Chapman, E., Baron-Cohen, S., Auyeung, B., Knickmeyer, R., Taylor, K., \& Hackett, G. (2006). Fetal testosterone and empathy: Evidence from the Empathy Quotient (EQ) and the "Reading the Mind in the Eyes" test. Social Neuroscience, 1(2), 135-148.

Cheah, E. (2009). An orchestra beyond borders. London: Verso Books.

Davis, M. H. (1994). Empathy: A social psychological approach. CO: Westview Press.

Delsing, M. J. M. H, ter Bogt, T. F. M., Engels, R. C. M. E., \& Meeus, W. H. J. (2008). Adolescents’ music preferences and personality characteristics. European Journal of Personality, 22, 109-130.

Digman, J. M. (1990). Personality structure: Emergence of the five-factor model. Annual Review of Psychology, 41, 417-440.

Dennett, D. C. (1989). The intentional stance. Cambridge, MA: MIT Press.

Don, A. J., Schellenberg, G. E., \& Rourke, B. P. (1999). Music and language skills of children with Williams syndrome. Child Neuropsychology, 5(3), 154-170.

Dunn, P. G., de Ruyter, B., \& Bouwhuis, D. G. (2012). Toward a better understanding of the relation between music preference, listening behavior, and personality. Psychology of Music, 40, 411-428.

Egermann, H., \& McAdams, S. (2013). Empathy and emotional contagion as a link between recognized and felt emotions in music listening. Music Perception: An Interdisciplinary Journal, 31(2), 139-156.

Fombonne, E. (2005). The changing epidemiology of autism. Journal of Applied Research in Intellectual Disabilities, 18(4), 281-294.

Fonagy, P. (2004). The developmental roots of violence in the failure of mentalization. Forensic Focus, 25 , 13-56.

Fonagy, P., Gergely, G., Jurist, E. L., \& Target, M. (2002). Affect regulation, mentalization and the development of the self. New York: Other Press.

Fonagy, P., Moran, G. S., Edgcumbe, R., Kennedy, H., \& Target, M. (1993). The roles of mental representations and mental processes in therapeutic action. The Psychoanalytic Study of the Child, 48, 9-48.

Fonagy, P., \& Target, M. (1997). Attachment and reflective function: Their role in self-organization. Development and Psychopathology, 9(4), 679-700. 
Fonagy, P., Target, M., Steele, H., \& Steele, M. (1998). Reflective-Functioning manual, version 5.0, for application to adult attachment interviews. London: University College London.

Fonagy, P., Steele, M., Steele, H., Moran, G. S., \& Higgitt, A. C. (1991). The capacity for understanding mental states: The reflective self in parent and child and its significance for security of attachment. Infant Mental Health Journal, 12(3), 201-218.

Frith, U. (1989). Autism: Explaining the enigma. Oxford, U.K.: Blackwell.

Gabrielsson, A. (2011). Strong experiences with music: Music is much more than just music. Oxford, UK: Oxford University Press. (Original work published in 2008).

George, D., Stickle, K., Rachid, F., \& Wopnford, A. (2007). The association between types of music enjoyed and cognitive, behavioral, and personality factors of those who listen. Psychomusicology, 19, 3256.

Goldenfeld, N., Baron-Cohen, S., \& Wheelwright, S. (2005). Empathizing and systemizing in males, females and autism. Clinical Neuropsychiatry, 2(6), 338-345

Goldstein, T. R., Wu, K., \& Winner, E. (2009). Actors are skilled in theory of mind but not empathy. Imagination, Cognition and Personality, 29(2), 115-133.

Greitemeyer, T. (2009). Effects of songs with prosocial lyrics on prosocial thoughts, affect, and behavior. Journal of Experimental Social Psychology, 45(1), 186-190.

Happé, F., \& Frith, U. (2006). The weak coherence account: detail-focused cognitive style in autism spectrum disorders. Journal of Autism and Developmental Disorders, 36(1), 5-25.

Harris, P., Johnson, C. N., Hutton, D., Andrews, G., \& Cooke, T. (1989). Young children's theory of mind and emotion. Cognition and Emotion, 3, 379-400.

Heaton, P. (2003). Pitch memory, labelling and disembedding in autism. Journal of Child Psychology and Psychiatry, 44, 543-551.

Heaton, P. (2005). Interval and contour processing in autism. Journal of Autism and Developmental Disorders, 35, 787-793.

Heaton, P., Hermelin, B., \& Pring, L. (1998). Autism and pitch processing: A precursor for savant musical ability? Music Perception, 291-305.

Huss, M., Verney, J. P., Fosker, T., Mead, N., \& Goswami, U. (2011). Music, rhythm, rise time perception and developmental dyslexia: Perception of musical meter predicts reading and phonology. Cortex, 47(6), 674-689.

Iversen, J.R., \& Patel, A.D. (2008) The Beat Alignment Test (BAT): Surveying beat processing abilities in the general population. In: Proceedings of the 10th International Conference on Music Perception and Cognition (ICMPC 10). Sapporo: Japan. p. 465.

Jurist, E. L. (2005). Mentalized affectivity. Psychoanalytic Psychology, 22(3), 426.

Juslin, P. N., \& Västfjäll, D. (2008). Emotional responses to music: The need to consider underlying mechanisms. Behavioral and Brain Sciences, 31(5), 559-575.

Kaplan, R. S., \& Steele, A. L. (2005). An analysis of music therapy program goals and outcomes for clients with diagnoses on the autism spectrum. Journal of Music Therapy, 42(1), 2-19. 
Kidd, D. C., \& Castano, E. (2013). Reading literary fiction improves theory of mind. Science, 342(6156), 377-380.

Kirschner, S., \& Tomasello, M. (2010). Joint music making promotes prosocial behavior in 4-year-old children. Evolution and Human Behavior, 31(5), 354-364.

Kreutz, G., Schubert, E., \& Mitchell, L. A. (2008). Cognitive styles of music listening. Music Perception, 26(1), 57-73.

Kübler-Ross, E. (1969). On death and dying. New York: Macmillan.

Lai, M. C., Lombardo, M. V., Chakrabarti, B., Ecker, C., Sadek, S. A., Wheelwright, S. J., ... \& BaronCohen, S. (2012). Individual differences in brain structure underpin empathizing-systemizing cognitive styles in male adults. Neuroimage, 61(4), 1347-1354.

Lamont, A. (2011). University students' strong experiences of music: Pleasure, engagement, and meaning. Musicae Scientiae, 15(2), 229-249.

Lamont, A. (2012). Emotion, engagement and meaning in strong experiences of music performance. Psychology of Music, 40(5), 574- 594.

Langmeyer, A., Guglhör-Rudan, A., \& Tarnai, C. (2012). What do music preferences reveal about personality? A cross-cultural replication using self-ratings and ratings of music samples. Journal of Individual Differences, 33(2), 119-130.

Lawrence, E. J., Shaw, P., Baker, D., Baron-Cohen, S., \& David, A. S. (2004). Measuring empathy: reliability and validity of the Empathy Quotient. Psychological Medicine, 34(5), 911-919.

Lenhoff, H. M., Perales, O., \& Hickok, G. (2001). Absolute pitch in Williams syndrome. Music Perception, $18(4), 491-503$.

Levitin, D. J., \& Bellugi, U. (1998). Musical abilities in individuals with Williams syndrome. Music Perception, 357-389.

Levitin, D. J., Menon, V., Schmitt, J. E., Eliez, S., White, C. D., Glover, G. H., ... \& Reiss, A. L. (2003). Neural correlates of auditory perception in Williams syndrome: an fMRI study. Neuroimage, 18(1), 74-82.

Lonsdale, A. J., \& North, A. C. (2009). Musical taste and ingroup favouritism. Group Processes \& Intergroup Relations, 12(3), 319-327.

McCrae, R. R., \& Costa, P. T., Jr. (2003). Personality in adulthood: A Five-Factor Theory perspective (2nd edition). New York: Guilford.

Miller, L. K. (1999). The savant syndrome: Intellectual impairment and exceptional skill. Psychological Bulletin, 125, 31-46.

Miu, A. C., \& Balteş, F. R. (2012). Empathy manipulation impacts music-induced emotions: A psychophysiological study on opera. PloS one, 7(1), e30618.

Motion Picture Association of America, Inc (2007). Entertainment industry market statistics. [Online]. Retrieved on 15 September 2011 from: http://www.mpaa.org/USEntertainmentIndustryMarketStats.pdf.

Müllensiefen, D., Gingras, B., Musil, J., \& Stewart, L. (2014). The musicality of non-musicians: An index for assessing musical sophistication in the general population. PloS One, 9(2), e89642. 
Nettle, D. (2007). Empathizing and systemizing: What are they, and what do they contribute to our understanding of psychological sex differences? British Journal of Psychology, 98(2), 237-255.

Peters, D. (2015). Musical empathy, emotional co-constitution and the "musical other". Empirical Musicology Review, 10(1), 2-15.

Premack, D. (1990). The infant's theory of self-propelled objects. Cognition, 36, 1-16.

Quintin, E. M., Bhatara, A., Poissant, H., Fombonne, E., \& Levitin, D. J. (2011). Emotion perception in music in high-functioning adolescents with autism spectrum disorders. Journal of Autism and Developmental Disorders, 41(9), 1240-1255.

Rabinowitch, T., Cross, I., \& Burnard, P. (2013). Long-term musical group interaction has a positive influence on empathy in children. Psychology of Music, 41(4), 484-498.

Rentfrow, P. J. (2012). The role of music in everyday life: Current directions in the social psychology of music. Social and Personality Psychology Compass, 6(5), 402-416.

Rentfrow, P. J., Goldberg, L. R., \& Levitin, D. J. (2011). The structure of musical preferences: A fivefactor model. Journal of Personality and Social Psychology, 100(6), 1139-1157.

Rentfrow, P. J., Goldberg, L. R., Stillwell, D. J., Kosinski, M., Gosling, S. D., \& Levitin, D. J. (2012). The song remains the same: A replication and extension of the MUSIC model. Music Perception, 30, 161-185.

Rentfrow, P. J., \& Gosling, S. D. (2003). The do re mi's of everyday life: The structure and personality correlates of music preferences. Journal of Personality and Social Psychology, 84, 1236-1256.

Rentfrow, P. J., \& McDonald, J. A. (2009). Music preferences and personality. In P. N. Juslin \& J. Sloboda (Eds.), Handbook of music and emotion (pp. 669-695). Oxford: Oxford University Press.

Rickson, D. J., \& Watkins, W. G. (2003). Music therapy to promote prosocial behaviors in aggressive adolescent boys - a pilot study. Journal of Music Therapy, 40(4), 283-301.

Sousa, M. D. R., Neto, F., \& Mullet, E. (2005). Can music change ethnic attitudes among children? Psychology of Music, 33(3), 304-316.

Strasberg, L. (1987). A dream of passion: The development of the method. New York: Plume.

Swann, W. B. Jr., Rentfrow, P. J., \& Guinn, J. S. (2002). Self-verification: The search for coherence. In M. Leary \& J. Tagney (Eds.), Handbook of self and identity (pp. 367-383). New York: Guilford Press.

Thompson, W. F., Russo, F. A., \& Quinto, L. (2008). Audio-visual integration of emotional cues in song. Cognition and Emotion, 22(8), 1457-1470.

Tsay, C. J. (2013). Sight over sound in the judgment of music performance. Proceedings of the National Academy of Sciences, 110(36), 14580-14585.

Vuoskoski, J. K., \& Eerola, T. (2012). Can sad music really make you sad? Indirect measures of affective states induced by music and autobiographical memories. Psychology of Aesthetics, Creativity, and the Arts, 6(204.10), 1037.

Vuoskoski, J. K., Thompson, W. F., McIlwain, D., \& Eerola, T. (2012). Who enjoys listening to sad music and why? Music Perception, 29(3), 311-317.

Whiten, A. (1991). Natural theories of mind. Oxford: Basil Blackwell. 
Wakabayashi, A., Baron-Cohen, S., \& Wheelwright, S. (2006). Are autistic traits an independent personality dimension? A study of the Autism-Spectrum Quotient (AQ) and the NEO-PI-R. Personality and Individual Differences, 41(5), 873-883.

Wakabayashi, A., Baron-Cohen, S., Wheelwright, S., Goldenfeld, N., Delaney, J., Fine, D., ... \& Weil, L. (2006). Development of short forms of the Empathy Quotient (EQ-Short) and the Systemizing Quotient (SQ-Short). Personality and individual differences, 41(5), 929-940.

Whipple, J. (2004). Music in intervention for children and adolescents with autism: A meta-analysis. Journal of music therapy, 41(2), 90-106.

Wöllner, C. (2012). Is empathy related to the perception of emotional expression in music? A multimodal time-series analysis. Psychology of Aesthetics, Creativity, and the Arts, 6(3), 214.

Zentner, M., Grandjean, D., \& Scherer, K. R. (2008). Emotions evoked by the sound of music: Characterization, classification, and measurement. Emotion, 8(4), 494-521.

Zweigenhaft, R.L. (2008). A do re mi encore: A closer look at the personality correlates of music preferences. Journal of Individual Differences, 29, 45-55. 